CZASOPISMO INŻYNIERII LĄDOWEJ, ŚRODOWISKA I ARCHITEKTURY JOURNAL OF CIVIL ENGINEERING, ENVIRONMENT AND ARCHITECTURE JCEEA, t. XXXIII, z. 63 (4/16), październik-grudzień 2016, s. 43-52

Dorota BZOWSKA ${ }^{1}$

\title{
RYZYKO PRZEGRZANIA BUDYNKÓW IZOLOWANYCH CIEPLNIE W OKRESIE LETNIM
}

\begin{abstract}
Wyznaczono, dla okresu letniego, dobowe zakresy temperatur wewnętrznych oraz liczby wymian powietrza wentylacyjnego w budynkach, których przegrody zewnętrzne są zaizolowane cieplnie. Wyniki obliczeń odnoszą się do obecnych warunków pogodowych i tych przewidywanych po ociepleniu klimatu. Wg przedstawionych scenariuszy IPCC, zmiany te mają nastąpić w ciągu dwóch najbliższych dekad. W obliczeniach przyjęto jedynie scenariusz, wg którego przewidywany wzrost temperatury jest najniższy i wyniesie $4^{0} \mathrm{C}$.

Przebiegi temperatury wewnętrznej i naturalną wymianę powietrza wentylacyjnego symulowano numerycznie $\mathrm{w}$ budynku jednorodzinnym o otwartym planie. Przepływ powietrza w budynku jest wynikiem jedynie działania parametrów pogody. W odniesieniu do wiatru, symulacje prowadzone są dla trzech trybów jego oddziaływania na system naturalnej wentylacji. Wiatr może intensyfikować przepływ powietrza przez budynek lub obniżać strumień powietrza. W skrajnych wypadkach powoduje odwrotny przepływ powietrza wentylacyjnego. Obliczenia uwzględniają także pogodę bezwietrzną, Brak wiatru często występuje przy wysokich letnich temperaturach. Budynek nie jest zacieniony.

Informacje uzyskane $\mathrm{z}$ prezentowanych $\mathrm{w}$ pracy przebiegów temperatury wewnętrznej i liczby wymian powietrza wentylacyjnego $(\mathrm{ACH})$ wskazują, że przyjmowanie wstępnych założeń projektowych bez uprzedniej analizy procesów cieplno-przepływowych zachodzących w budynkach jest działaniem nieuzasadnionym. Budynki obecnie projektowane, wznoszone i termomodenizowane będą musiały sprostać wymaganiom komfortu cieplnego nie tylko teraz, ale także w okresie spodziewanego ocieplenia klimatu. Z przegrzaniem wnętrza, w okresie letnim, borykają się obecnie mieszkańcy budynków, w tym także budynków niskoenergetycznych w sezonie grzewczym.
\end{abstract}

Słowa kluczowe: przegrzanie budynków, zmiany klimatu, naturalna wentylacja, przepływ odwrotny powietrza przez budynek, proces projektowy, symulacje numeryczne procesów wymiany ciepła i powietrza wentylacyjnego

\section{Wprowadzenie}

Asumptem to napisania pracy był europejski projekt o nazwie IDES-EDU: „Master and Post-Graduate education and training in multi-disciplinary

\footnotetext{
${ }^{1}$ Dorota Bzowska, Politechnika Warszawska, Instytut Budownictwa, Płock 09-400, Łukasiewicza 17; dor.bzowska@gmail.com
} 
teams"[2]. Projekt stanowi wytyczne do tworzenia, w ramach programów studiów magisterskich i podyplomowych, w krajach członkowskich UE, interdyscyplinarnych zespołów badawczo-projektowych. Praca zespołu złożonego z inżynierów zajmujących się różnymi dyscyplinami związanymi z tworzeniem projektu budowlanego oraz, w razie potrzeby, $\mathrm{z}$ badaczy procesów zachodzących w obiektach budowlanych, mogłaby gwarantować poprawny tok procesu projektowego i w konsekwencji powstanie przyjaznego mieszkańcom i środowisku budynku. Według IDES-EDU, integracyjny proces kształcenia, na potrzeby projektu budowlanego, obejmowałby zarówno architektów jak i mechaników, inżynierów budowlanych, energetyków. Zespół ten miałby pracować wspólnie przez cały czas pracy nad projektem [2,6]. Proponowane w IDES-EDU podejście do projektu, w praktyce należy do rzadkości. Dość powszechne jest zatrudnianie ekspertów w ostatniej fazie projektu, kiedy kluczowe decyzje projektowe są już podjęte [11]. A więc w fazie kiedy wszelkie decyzje energetyczne $\mathrm{i}$ te kształtujące komfort cieplny budynku są przesądzone. Bardzo często przyjęte rozwiązania architektoniczne redukują zużycie energii w okresie grzewczym natomiast generują jej pobór w okresie letnim. Obecnie, nie tylko wartość współczynnika przenikania ciepła „U” i współczynnik kształtu budynku wyznaczają straty ciepła z budynku. Stąd też ocena jakości zużycia energii we wszystkich porach roku jak i parametry komfortu w budynkach winny podlegać analizie.

Proponowane w projekcie IDES-EDU rozwiązanie jest tym bardziej naglące bo po roku 2021 rozwój budownictwa będzie związany z budownictwem blisko zero energetycznym zarówno w odniesieniu do budynków nowopowstających jak i tych termomodernizowanych. Zadaniem interdyscyplinarnych zespołów projektowych będzie zatem optymalizacja zapotrzebowania na energię tak dla okresu grzewczego jak i w okresie upałów. Obecnie wiele budynków zaizolowanych cieplnie, pozbawionych znaczącej masy akumulacyjnej i wyposażonych $\mathrm{w}$ naturalny system wentylacyjny, jest w okresie lata przegrzewane. Zapewnienie obecnie poprawnego mikroklimatu w budynku jest istotne, bo aktualnie wznoszone budynki będą musiały „odpowiedzieć” na przewidywane ocieplenie klimatu. Jeśli w obecnym klimacie występuje letnie przegrzanie to proces ten zaostrzy się po wzroście temperatury otoczenia. Według scenariusza A1F1 średnia temperatura w przeciągu XXI wieku wzrośnie o $4^{0} \mathrm{C}$. Scenariusz A1F1 przewiduje najłagodniejsze zmiany klimatu, inny scenariusz przewiduje wzrost temperatury o $11^{\circ} \mathrm{C}[4,13,14]$.

Obecnie, kiedy pomieszczenia w budynkach, także niskoenergetycznych, są przegrzewane proponuje się montaż klimatyzatorów. Zasadność takiego rozwiązania powinny wykazać pomiary, które wykażą jak często i jak długa w czasie dnia temperatura $\mathrm{w}$ pomieszczeniu przekracza temperaturę komfortu cieplnego.

Przedstawione $\mathrm{w}$ pracy, zmienne $\mathrm{w}$ obrębie doby, przebiegi temperatury wewnętrznej i liczby wymian powietrza wentylacyjnego wyznaczono dla lipca. Symulacje numerycznych wykonano programem autorskim. 


\section{Bilans energetyczny i masowy budynku, założenia modelowe}

Badanie procesów termodynamicznych, które zachodzą w obiektach budowlanych wymaga rozwiązania układu dwóch równań. Pierwsze (1), podane poniżej, opisuję pełną wymianę ciepła i dyfuzję masy i jest uzupełnione równania (2), które pozwala obliczyć strumień objętości powietrza przepływającego przez budynek [8].

$$
\begin{aligned}
& \mathrm{V} \cdot \rho_{\mathrm{i}} \cdot \mathrm{c}_{\mathrm{v}} \cdot \frac{\mathrm{dT} \mathrm{T}_{\mathrm{i}}}{\mathrm{d} \tau}=\Phi+\sum_{\mathrm{I}=1}^{\mathrm{n}} \mathrm{h}_{\mathrm{i}_{\mathrm{I}}} \cdot \mathrm{F}_{\mathrm{I}} \cdot\left(\mathrm{T}_{\mathrm{S}_{\mathrm{I}}}-\mathrm{T}_{\mathrm{i}}\right)+ \\
& \quad+\sum_{\mathrm{K}=1}^{\mathrm{m}} \mathrm{U}_{\mathrm{ok}_{\mathrm{K}}} \cdot \mathrm{A}_{\mathrm{ok}_{\mathrm{K}}} \cdot\left(\mathrm{T}_{\mathrm{o}}-\mathrm{T}_{\mathrm{i}}\right)+\dot{\mathrm{V}}_{\mathrm{m}} \cdot \mathrm{c}_{\mathrm{p}} \cdot\left(\mathrm{T}_{\mathrm{o}}-\mathrm{T}_{\mathrm{i}}\right) \\
& \dot{\mathrm{V}}_{\mathrm{m}}=\mathrm{C}_{\mathrm{d}} \cdot \mathrm{A} \cdot \rho_{\mathrm{o}} \cdot \sqrt{\mid 2 \cdot \mathrm{g} \cdot \mathrm{h} \cdot \frac{\mathrm{T}_{\mathrm{i}}-\mathrm{T}_{\mathrm{o}}}{\mathrm{T}_{\mathrm{o}}} \pm 2 \Delta \mathrm{p}_{\mathrm{v}}}
\end{aligned}
$$

Lewa strona równania (1) opisuje zmianę energii wewnętrznej powietrza wewnętrznego o temperaturze $T_{i} W$ objętości $V$, gęstości $\rho_{i}$ i cieple właściwym przy stałej objętości $c_{v}$. Po prawej stronie równania (1) człon - $Q_{c}$ jest wynikową sumą strumieni ciepła dopływających i traconych przez pomieszczenie, a mianowicie strumieni ciepła: z urządzeń cieplnych, z urządzeń zasilanych elektrycznie, od promieniowania krótkofalowego, głównie jest to promieniowanie słoneczne, pozyskiwane za pośrednictwem przegród przezroczystych, od użytkowników pomieszczeń oraz straty ciepła do podłoża. Drugi człon równania opisuje proces przejmowania ciepła $\mathrm{w}$ pomieszczeniu, gdzie $\mathrm{T}_{\mathrm{s}}$ jest temperaturą powierzchni ściany. Trzeci dotyczy wymiany ciepła przez okno. Czwarty człon wyraża zmianę entalpii, związaną ze strumieniem masy powietrza wentylacyjnego, o natężeniu przepływu $\dot{\mathrm{V}}_{\mathrm{m}}\left[\mathrm{kg} \cdot \mathrm{s}^{-1}\right]$. Powietrze wpływa do pomieszczenia przy temperaturze otoczenia $T_{o} i$ opuszcza je przy temperaturze $T_{i}$.

Strumień wymiany konwekcyjnej, pomiędzy powietrzem w pomieszczeniu a każdą z otaczających go ścian, jest zależny od temperatury ich powierzchni, dla których bilans energetyczny przedstawia się następująco:

$$
-\left.\lambda \cdot \operatorname{gradT}\right|_{\mathrm{s}}=\mathrm{h}_{\mathrm{i}} \cdot\left(\mathrm{T}_{\mathrm{s}}-\mathrm{T}_{\mathrm{i}}\right)-\alpha_{\mathrm{s}} \cdot \Phi_{\mathrm{o}}+\Phi_{\mathrm{pr}}
$$

W równaniu (3) występują następujące współczynniki: $\lambda$ - przewodzenia ciepła warstwy ściany bezpośrednio przy powierzchni, $\alpha_{\mathrm{s}}-$ absorpcyjności ściany, $h_{i}-$ przejmowania ciepłą. $\Phi_{\mathrm{pr}}, \Phi_{0}-$ strumień promieniowania długofalowego i krótkofalowego, odpowiednio. 
Spadek ciśnienia, w równaniu (2), wynikający z różnicy gęstości powietrza, który powstaje pomiędzy podłogą i stropem na wysokości h wynosi $\left(\mathrm{g}^{\prime} \mathrm{h}\right)^{1 / 2}$, gdzie $\mathrm{g}^{\prime}=\mathrm{g} \Delta \mathrm{T} / \mathrm{T}_{\mathrm{o}}=\mathrm{g} \Delta \rho / \rho_{\mathrm{o}}$. Spadek ciśnienia, wywoływany wiatrem uwzględnia człon ciśnieniowy $\Delta \mathrm{p}_{\mathrm{v}} / \rho_{\mathrm{o}}$. Dokładny opis i analizę równania 2 , łącznie z wyznaczeniem bifurkacji przepływu, można znaleźć w $[3,8]$.

Zakłada się jednowymiarowe pole temperatur w stropie i ścianach budynku. Równanie przewodnictwa (4) rozwiązuje się z nieustalonymi warunkami brzegowymi III i IV rodzaju.

$$
\frac{\partial \mathrm{T}}{\partial \tau}=\frac{\lambda}{\rho \cdot c} \cdot \frac{\partial^{2} \mathrm{~T}}{\partial \mathrm{x}^{2}}
$$

- po stronie wewnętrznej temperatura w pomieszczeniu jest parametrem skupionym, będącym wynikiem wszystkich omawianych oddziaływań energetycznych, oraz spełniony jest warunek brzegowy:

$$
\mathrm{h}_{\mathrm{i}} \cdot\left[\mathrm{T}_{\mathrm{sc} 1}-\mathrm{T}_{\mathrm{i}}\right]=-\lambda_{1} \cdot\left(\frac{\partial \mathrm{T}}{\partial \mathrm{x}}\right)_{1}
$$

gdzie indeks „1” oznacza pierwszą warstwę,

- dla przegrody wielowarstwowej warunek brzegowy na granicy warstw jest warunkiem IV rodzaju:

$$
-\lambda_{j} \cdot\left(\frac{\partial T}{\partial x}\right)_{j}=-\lambda_{j+1} \cdot\left(\frac{\partial T}{\partial x}\right)_{j+1}
$$

- po stronie zewnętrznej zastosowano warunek brzegowy III rodzaju, z dodatkowym członem, uwzględniającym padający na ścianę i przez nią pochłaniany strumień promieniowania słonecznego. Zarówno strumień promieniowania, jak i temperatura otoczenia, są funkcjami czasu.

$$
\alpha_{\mathrm{s}} \cdot \mathrm{G}_{\beta}-\mathrm{h}_{\mathrm{o}} \cdot\left[\mathrm{T}_{\mathrm{scn}}-\mathrm{T}_{\mathrm{o}}\right]=-\lambda_{\mathrm{n}} \cdot\left(\frac{\partial \mathrm{T}}{\partial \mathrm{x}}\right)_{\mathrm{n}}
$$

gdzie indeks „,” oznacza ostatnią, zewnętrzną warstwę przegrody.

Wartości strumienia ciepła, pochodzące z promieniowania słonecznego, aproksymowane są z 15 minutowych danych tablicowych zliczanych przez stację IMGW w Warszawie.

Algorytm obliczeń oparty jest na metodzie różnic skończonych. Równania opisujące wymianę ciepła i wymianę powietrza są rozwiązywane równocześnie. 
Temperatura wewnętrzna obliczona $\mathrm{z}$ równania wymiany ciepła jest wprowadzona do równań przepływu powietrza w następnym kroku czasowym. Zabieg ten pozwala na wyznaczenie w kolejnym kroku, temperatury wewnętrznej, która uwzględnia zarówno wymianę ciepła jak i wymianę powietrza.

Obliczenia wykonano dla następujących uśrednionych, po latach i miesiącu, wartości parametrów pogody w lipcu dla Warszawy. Przebieg dobowy obu parametrów pogody opisuje funkcja trygonometryczna. Jej wartość średnia dla temperatury otoczenia wynosi $-(17,27)^{0} \mathrm{C}$, amplituda $-(4,04)^{0} \mathrm{C}$ a przesunięcie w stosunku do godziny 6 rano (funkcja o tej godzinie się zeruje) równe jest $(-8,42)$ h. Oznacza to, że temperatura zewnętrzna w lipcu osiąga swoje maksimum o godzinie 14,42 . Wiatr północny na wysokości $1 \mathrm{~m}$ charakteryzuje się wartością średnią - $(1,03) \mathrm{m} / \mathrm{s}$, amplitudą - $(0,25) \mathrm{m} / \mathrm{s}$, przesunięciem w stosun$\mathrm{ku}$ do minimum funkcji równym $(-9,5)$. Wiatr południowy na wysokości $4 \mathrm{~m}$ ma wartość średnią - $(1,27) \mathrm{m} / \mathrm{s}$, amplitudę - $(0,30) \mathrm{m} / \mathrm{s}$, przesunięcie równe $(-7,0) \mathrm{h}$.

\section{Charakterystyka obiektu budowlanego}

Badanie zmienności temperatury powietrza wewnętrznego i intensywności wymiany powietrza wentylacyjnego przeprowadzono $\mathrm{w}$ budynku jednostrefowym o wymiarach $5 \mathrm{~m} \times 5 \mathrm{~m} \times 3 \mathrm{~m}$. Budynek jest wyposażony w wentylację naturalną. Budynek posiada wewnętrzną masę termiczną, która zwiększa akumulację ciepła. W okresie letnim do odprowadzenia ciepła z budynku wykorzystuje się kalibrowane otwory wentylacyjne. Otwory zostały umieszczone w przeciwległych ścianach. Otwory doprowadzające powietrze do budynku powinny być usytuowane w północnej ścianie. Taka lokalizacja, otworu w okresie letnim, pozwala uniknąć wpływu bezpośredniego promieniowana słonecznego. Przy innym umiejscowieniu otworu, okresowy wzrost temperatury zewnętrznej może przekroczyć wartość temperatury wewnętrznej, powodując tym samym zaburzenia w przepływie powietrza przez budynek. Otwór dopływowy, dolny, dla powietrza wentylacyjnego, poddawany jest zatem działaniu wiatru północnego (assisting [8]). Otwór górny stanowi wylot. Przy wietrze południowym, tzw. przeciwnym (opposing [8]), funkcje otworów są odwrotne, o ile wypór termiczny powietrza nie góruje nad spadkiem ciśnienia wywoływanym parciem wiatru południowego. W każdej sytuacji wiatr, działający na przegrodę budynku z dolnym otworem dopływowym, intensyfikuje przepływ powietrza. Parcie wiatru, na ścianę z otworem górnym, osłabia lub wręcz odwraca przepływ powietrza przez budynek. Testowany numerycznie budynek został zbudowany ok. 40 lat temu. Opór cieplny przegród zewnętrznych nie spełnia aktualnych wymogów ochrony cieplnej. Opór przenikania dla stropodachu murowanego, który został w międzyczasie ocieplony $4 \mathrm{~cm}$ wełny mineralnej i ponownie pokryty papą, wynosi $1.144 \mathrm{~m}^{2} \cdot \mathrm{K} / \mathrm{W}$. Ściany pionowe o grubości $38 \mathrm{~cm}$, zbudowane z cegły, mają opór cieplny tylko $0.664 \mathrm{~m}^{2} \cdot \mathrm{K} / \mathrm{W}$. Wewnętrzna warstwa akumulacyjna (masa termiczna) jest odpowiednikiem przegrody ceglanej o grubości $20 \mathrm{~cm}$ i jej po- 
jemność cieplna osiąga wartość $1134 \mathrm{~kJ} / \mathrm{kg} \cdot \mathrm{K}$ Pojemność cieplna całego budynku równa jest $4838 \mathrm{~kJ} / \mathrm{kg} \cdot \mathrm{K}$. Przegrody zewnętrzne mają orientację: południową, północną, wschodnia i zachodnią. Okna zespolone o współczynniku przenikania ciepła równym $1.6 \mathrm{~W} /\left(\mathrm{m}^{2} \cdot \mathrm{K}\right)$ mają powierzchnię $1,5 \mathrm{~m}^{2}$ i znajdują się $\mathrm{w}$ ścianie: $\mathrm{S}, \mathrm{E}$ i W. Udział powierzchni okien w powierzchni ściany wynosi 0,1 . Przyjęta $\mathrm{w}$ obliczeniach moc cieplna, pochodząca $\mathrm{z}$ zainstalowanych urządzeń $\mathrm{i}$ od mieszkańców wynosi $300 \mathrm{~W}$.

\section{Analiza wyników i wnioski}

Analizując powołaną $\mathrm{w}$ artykule literaturę znajdujemy szereg rozwiązań ograniczających przegrzewanie budynku o wysokim oporze cieplnym i niskiej pojemności cieplnej przegród nieprzezroczystych. Poczynając od najprostszego rozwiązania jakim jest zacienienie okien po rozwiązania, które wynikają z symulacji procesów cieplno-przepływowych specjalistycznymi programami numerycznymi. Programy te umożliwiają symulację komfortu cieplnego w budynkach termomodernizowanych pod kątem spodziewanych zmian klimatycznych. Na szeroką skalę, w celu zawansowanych badań nad komfortem cieplnym, tworzone są bazy danych dla budynków w okresie letnim. Pomiary poligonowe pozwalają zidentyfikować, w zależności od typu i lokalizacji budynku, czas i długość trwania wysokich temperatur w obiekcie. Wśród badaczy istnieje świadomość konieczności antycypowania tego zjawiska poprzez konstruowanie poprawnych

a)

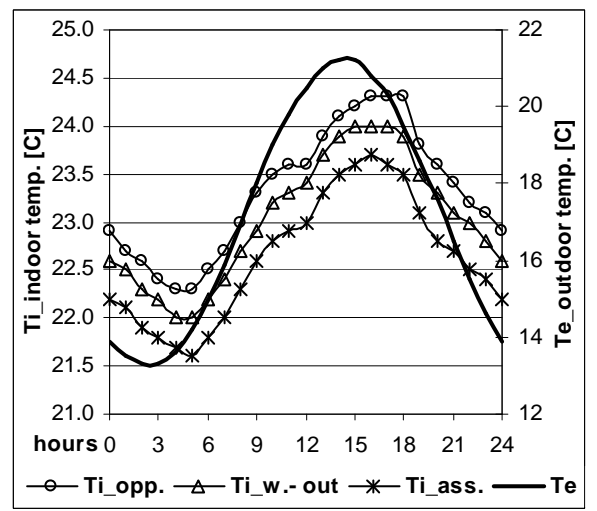

b)

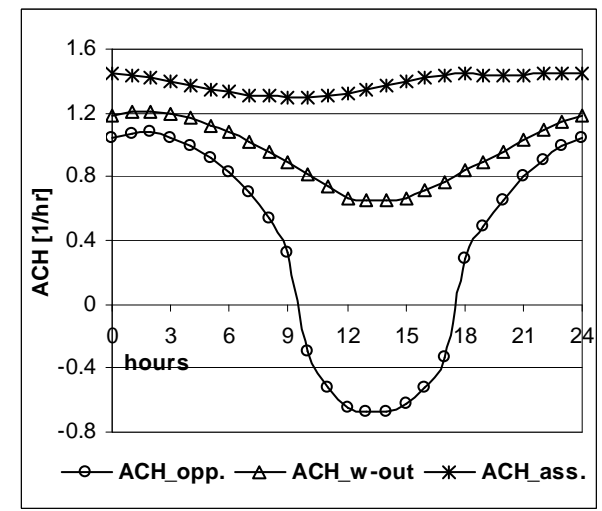

Rys. 1. Dobowe przebiegi dla lipca a) temp. zewnętrznej - Te i temp. wewnętrznej Ti; b) liczba wymian powietrza wentylacyjnego $(\mathrm{ACH})$ dla trzech form aktywności wiatru. Ti_ass -wiatr wspomagający, północny, Ti_opp - południowy, przeciwny, Ti_w-out - bez wiatru. Budynek nie jest cieplnie izolowany

Fig. 1. Time history in July for the mean a) outdoor temp. -Te and indoor temp. -Ti; b)ACH at the three forms of wind appearance. Ti_ass - assistig wind - the north one, Ti_opposing, the south one, Ti_w-out - no wind. The building is not thermally insulated 
założeń projektowych budynku. Założeń rozumianych nie tylko w sensie konstrukcyjnym ale także jako wymagań energetycznych dotyczących utrzymania komfortu cieplnego $[1,5,7,9,10,12]$. Stąd program UE dotyczący szkolenia interdyscyplinarnych zespołów projektowych w dziedzinie budownictwa.

Przedstawione w pracy wstępne wyniki obliczeń wpisują się w ogólną tendencję badań nad zjawiskiem przegrzania. Wykresy na rys. 1 ilustrują bazowy proces cieplno-przepływowy budynku z okresu poprzedzającego zabiegi termomodernizacyjne. Wówczas nie występowało zjawiska przegrzania wnętrza budynku przy standardowych warunkach eksploatacyjnych. Zarówno temperatury wewnętrzne jak i wymiana powietrza przepływającego przez budynek była zadawalająca $\mathrm{z}$ wyjątkiem okresu kiedy występował przepływ odwrotny powietrza. Temperatury wewnętrzne osiągały swoje maksimum w godzinach popołudniowych i mieściły się w zakresie komfortu cieplnego. Najwyższe temperatury obserwuje się przy tłumieniu przepływu wiatrem przeciwnym, południowym. Odprowadzanie ciepła z budynku odbywało poprzez wentylację i przez przenikania przez obudowę budynku. Występował wówczas proces nocnego chłodzenia.

Rys. 2 ilustruje stan cieplno-przepływowy w budynku z $15 \mathrm{~cm}$ warstwą izolacyjną, której opór cieplny wynosi $3,57 \mathrm{~m}^{2} \mathrm{~K} / \mathrm{W}$. Z uwagi na wytłumienie strat ciepła przez zaizolowane cieplnie przegrody ,ciężar” odprowadzenia ciepła spoczywa na wentylacji. Średnie wartości parametrów klimatu są takie same jak przy budynku niedocieplonym. Średnia, maksymalna wartość temperatury otoczenia w lipcu wynosi niewiele ponad $21^{\circ} \mathrm{C}$. $\mathrm{Z}$ racji wyższej temperatury we-

a)

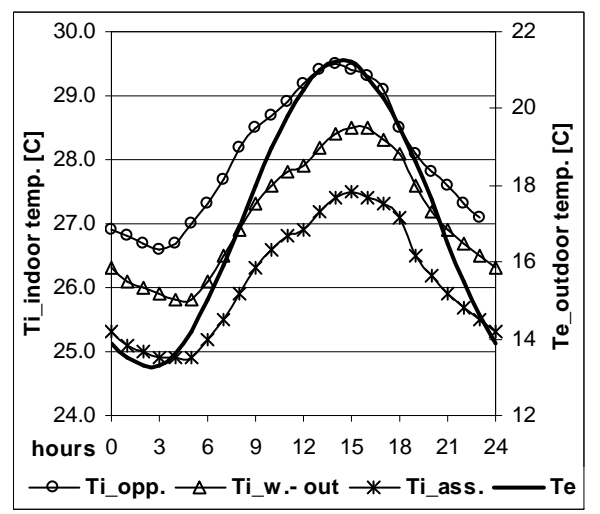

b)

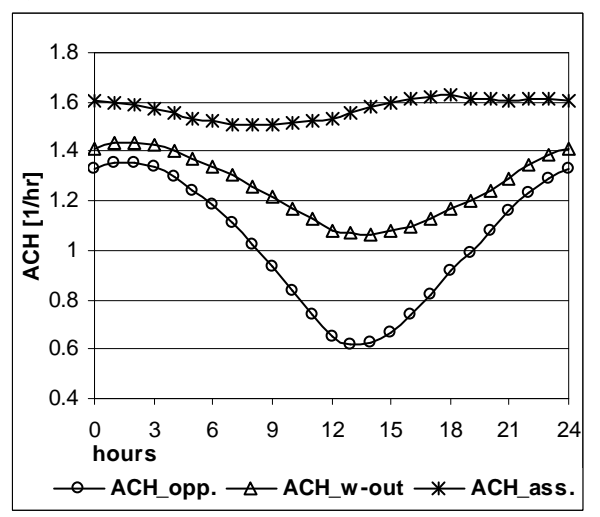

Rys. 2. Dobowe przebiegi dla lipca a) temp. zewnętrznej - Te i temp. wewnętrznej Ti; b) liczba wymian powietrza wentylacyjnego $(\mathrm{ACH})$ dla trzech form aktywności wiatru. Ti_ass - wiatr wspomagający, północny, Ti_opp - południowy, przeciwny, Ti_w-out - bez wiatru. Budynek jest ocieplony $15 \mathrm{~cm}$ izolacji

Fig. 2. Time history in July for the mean a) outdoor temp. - Te and indoor temp. - Ti; b) ACH at the three forms of wind appearance. Ti_ass - assisting wind - the north one, Ti_opposing, the south one, Ti_w-out - no wind. The building is covered with $15 \mathrm{~cm}$ of thermal insulation 
wnętrznej, generowany jest większy wypór termiczny, który intensyfikuje przepływ powietrza przez budynek i uniemożliwia powstawanie przepływu odwrotnego. Intensywniejsza wentylacja nie jest jednak w stanie przeciwdziałać powstawaniu wyższych temperatur w budynku. Przekraczają one poziom komfortu cieplnego w godzinach popołudniowych. Najwyższa temperatura występuje przy wietrze południowym, bo wtedy wentylacja działa najsłabiej. Około godziny 14 temperatura $\mathrm{w}$ budynku sięga niemal $30^{\circ} \mathrm{C}$ przy czym, temperatury powyżej $29^{\circ} \mathrm{C}$ utrzymują się pomiędzy godziną 11 a 18 . Komfort cieplny utrzymany jest przez całą dobę tyko przy wietrze wspomagającym. Powietrze ma w tym wypadku bardzo wyrównany przepływ przez budynek.

Natomiast symulacje przeprowadzone w okresie wzrostu temperatury otoczenia tj. ocieplenia klimatu wskazują, że nawet w najbardziej sprzyjających wietrznie warunkach, temperatura wewnętrzna w godzinach pomiędzy 12 a 18 przekroczy $31^{\circ} \mathrm{C}$. Najniższa, w tym przypadku temperatura, tj. $28,8^{\circ} \mathrm{C}$ wystąpi jedynie nad ranem. O północy wyniesie aż $29^{\circ} \mathrm{C}$. Wówczas przepływ powietrza przez budynek, przy wietrze północnym, będzie wyrównany i liczba wymian powietrza wentylacyjnego $(\mathrm{ACH})$ wyniesie 1,6. W przypadku braku wiatru, wymiana powietrza wentylacyjnego będzie kształtowana jedynie wyporem termicznym i w środkowych godzinach doby będzie najniższa. W nocy wyniesie około 1,4 wymiany na godzinę. Stąd i temperatura wewnętrzna będzie wyższa w porównaniu do sytuacji kiedy wieje wiatr północny. W ciągu dnia temperatura przekroczy $32^{\circ} \mathrm{C}$. Natomiast przy wietrze południowym, wytłumiany jest przepływ powietrza wentylacyjnego i temperatura w godzinach popołudniowych jest wyższa niż $33^{\circ} \mathrm{C}$. Temperatura minimalna występuje nad ranem i przekracza $30^{\circ} \mathrm{C}$. Są to wartości osiągane przy przewidywanym, najmniejszym wzroście temperatury. Wyniki symulacji przedstawiono na rys. 3 .

Badany obiekt jest wyposażony $w$ okna o powierzchni standardowej tj., udziale równym 0,15 powierzchni podłogi a przeszklenie nie jest pokryte powłoką niskoemisyjną. Wydawane są opinie, że jedynie wentylacja mechaniczna może rozwiązać problem przegrzania. Powstanie wówczas problem energetyczny. Wydaje się zasadne wyposażanie budynków w systemy zawansowanej wentylacji naturalnej - AVN lub tylko elementy tego systemu. Systemy AVN pracują, z powodzeniem w obiektach, także użyteczności publicznej, nawet o wielotysięcznej kubaturze. We wstępnych założeniach projektowych można także rozważyć gruntowy wymiennik ciepła, który we współpracy z rekuperatorem przynosi bardzo wymierne rezultaty energetyczne w sezonie grzewczym i schładza budynek w lecie. Obniżenie pojemności cieplnej przegród nieprzezroczystych oraz zwiększenie przeszkleń, w obecnie wznoszonych domach jednorodzinnych, bardzo „uwrażliwiło” wnętrze budynku na wysokie temperatury otoczenia. 
a)

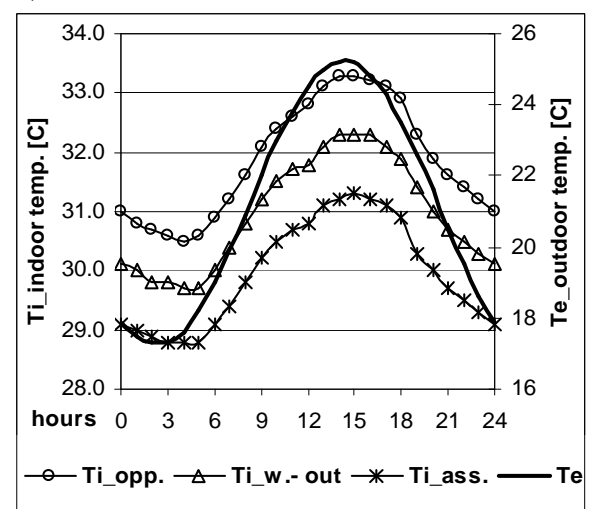

b)

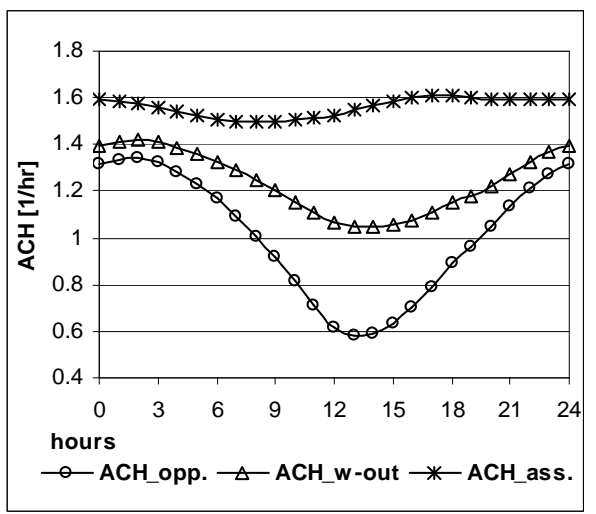

Rys. 3. Dobowe przebiegi dla lipca a) temp. zewnętrznej - Te wyższa $4^{0} \mathrm{C}$ i temp. wewnętrznej - Ti; b) liczba wymian powietrza wentylacyjnego (ACH) dla trzech form aktywności wiatru. Ti_ass -wiatr wspomagający, północny, Ti_opp - południowy, Ti_w-out - bez wiatru. Budynek jest ocieplny $15 \mathrm{~cm}$ izolacji

Fig. 3. Time history in July for the mean a) outdoor temp. - Te higher of 4 deg. and indoor temp. Ti; b) $\mathrm{ACH}$ at the three forms of wind appearance. Ti_ass - assisting wind - the north one, Ti_opposing, the south one, Ti_w-out - no wind. The building is covered with $15 \mathrm{~cm}$ of thermal insulation

\section{Literatura}

[1] Beizaee A., Lomas K., National survey of summertime temperatures and overheating risk in English homes, Building \& Environment 65 (2013) 1-14.

[2] Brunsgaard C., et al, Integrated energy design - Education and training in crossdisciplinary teams implementing energy performance of buildings directive (EPBD), Building \& Environment 72 (2014) 1-14.

[3] Bzowska D. Unsteady heat and air exchange processes in buildings with different material structure of partitions, in Polish, Inst. of Fundamental Technological Research Reports, PAS 2/2007.

[4] Bzowska D. Changes in temperature in buildings in response to the changing climate, in Polish, Technical Transactions, 2/B/2012 (3), 37-44.

[5] Coley D., Kershaw T., Changes in internal temperatures within the built environment as a response to a changing climate, Building \& Environment 45,(2010) 89-93.

[6] Kim T., Todorovic M., Tuning control of building glazing's transmittance dependence on the solar radiation wavelenght to optimaze daylighting and building's energy efficiecy, Energy \& Buildings 63 (2013) 108-118.

[7] Kisilewicz T., The influence of resistive, dynamic and spectral features of the building walls on the thermal balance of the low energy buildings, Monography, in Polish, Univ. press, PK, 2008.

[8] Li Y., Delsante A., Natural ventilation induced by combined wind and thermal forces, Building \& Environment, 36 (2001), 59-71.

[9] Porritt S.M. et al, Ranking of interventions to reduce dwelling overheating during heat waves,Energy \& Buildings55(2012)16-27. 
[10] Sailor D., Risks of summertime extreme thermal conditions in buildings as a result of climate change and exacerbation of urban heat islands, Building \& Environment 78 (2014) 81-88.

[11] Santos R. et al, Assessment of building operational energy at early stages of design. A monthly quasi-steady-state approach, Energy \& Buildings 79(2014) 58-73.

[12] Yingchun J. Assessing overheating of the UK existing dwellings. A case study of replica Victorian end terrace house, Building \& Environment 77(2014) 1-11.

[13] Intergovernmental Panel on Climate Change( www.ipcc.ch).

[14] UKCIP (www.ukcip.org.uk/ukcp09ukcip02, dostęp maj 2016).

\title{
RISKS OF SUMMERTIME OVERHEATING IN BUILDINGS THERMALLY INSULATED
}

\begin{abstract}
S u m m a r y
Thermally insulated buildings equipped with natural ventilation create overheating risk during summertime. However in these dwellings energy demand is reduced in heating season but in summer months thermal comfort can be hardly kept without additional cooling devices. In such a case the cooling energy can consume the energy profit gained from the reduction of heating energy. To examine thermal conditions in such a building the unsteady heat and air exchange processes were simulated for the hottest month that is July, in Warsaw. The climate in this part of Europe can be assumed as a moderate European climate. The examined building suits an open space single family house and is fitted with the heat accumulating mass. As the building is naturally ventilated three forms of ventilation airflow were considered - with assisting and opposing winds and no wind appearance. The algorithm of computations for the unsteady processes in the examined building was based on the finite differences method, where feedback between the thermal model and the airflow model was applied. The time history for indoor temperature and air exchange are presented in the paper. The results of computer simulation can help to designed the building well even for the hot periods.
\end{abstract}

Keywords: overheating in buildings, changing climate, natural ventilation, reversed flows, designing processes, numerical simulation of heat and air exchange

DOI:10.7862/rb.2016.246

Przestano do redakcji: $30.06 .2016 r$.

Przyjęto do druku: 20.12.2016 r. 